\title{
A PERCEPÇÃO DOS EDUCADORES QUANTO AO SEU PAPEL NA PROMOÇÃO DE HÁBITOS E ESTILOS DE VIDA SAUDÁVEIS NO AMBIENTE ESCOLAR
}

\author{
Elaine Cristina Carraro ${ }^{1}$ \\ https://orcid.org/0000-0002-6660-5382
}

Eliézer Costa Militão²
https://orcid.org/0000-0002-2398-7958

Helena Brandão Viana ${ }^{3}$ https://orcid.org/0000-0002-2018-202X

\begin{abstract}
RESUMO: Embora o crescimento econômico seja de grande importância para o novo conceito de progresso, pesquisas recentes apontam que este parece não ser suficiente para a qualidade de vida. Este trabalho traz à tona a percepção de professores sobre o seu papel na promoção de valores, hábitos e estilo de vida saudável, através de uma pesquisa de campo, onde chegou-se à conclusão de que apesar de os professores compreenderem a necessidade da promoção da saúde no ambiente escolar, parecem não compreender o seu papel nesse tema. A ampliação do envolvimento de governo e comunidades na formação profissional específica e interdisciplinar dos professores é uma necessidade marcante quando se deseja a promoção da saúde na escola e na comunidade, como preconiza a OMS.
\end{abstract}

PALAVRAS-CHAVE: educador, saúde, escola, estilo de vida.

\footnotetext{
${ }^{1}$ Doutora nos cursos de Pedagogia e Administração, Coordenadora de Pesquisa e Extensão, UNASP-HT, Hortolândia , SP, Brasil, lainecar@yahoo.com.br

${ }^{2}$ Mestrando no Programa de Mestrado Profissional em Educação do UNASP-EC, Engenheiro Coelho, SP, Brasil, eliezer.militao@gmail.com

${ }^{3}$ Doutora no Programa de Mestrado Profissional em Educação do UNASP-EC, SP, Brasil, hbviana2@gmail.com Rev. Fac. Educ. (Univ. do Estado de Mato Grosso), Vol. 32, Ano 17, № 2, p. 189-213, jul./dez., 2019 (Epub Ahead of Print 15 set., 2019).
} 


\section{THE PERCEPTION OF TEACHERS ON THEIR ROLE IN THE PROMOTION OF HEALTHY HABITS AND LIFELY STYLES IN THE SCHOOL ENVIRONMENT}

ABSTRACT: Although economic growth has great importance for the new concept of progress, recent research points out that this does not seem to be enough to solve have quality of life. With this work we bring to the fore the teachers' perception of their role in promoting values, habits and a healthy lifestyle through a field research, when it was concluded that although teachers understand the need to promote health in the school environment, do not seem to understand their role in this area. The expansion of the involvement of government and communities in the specific and interdisciplinary professional training of teachers is a marked need when health promotion in school and in the community is desired, as advocated by WHO.

KEYWORDS: educator, health, school,lifestyle.

\section{A PERCEPCIÓN DE LOS EDUCADORES DE SU PAPEL EN LA PROMOCIÓN DE HÁBITOS Y ESTILOS DE VIDA SALUDABLES EN EL ENTORNO ESCOLAR}

RESUMEN: Aunque el crecimiento económico es de gran importancia para el nuevo concepto de progreso, investigaciones recientes indican que no parece ser suficiente para la calidad de vida. Este trabajo saca a la luz la percepción de los maestros sobre su papel en la promoción de valores, hábitos y estilo de vida saludable, a través de una investigación de campo, que concluyó que aunque los maestros comprenden la necesidad de promover salud en el entorno escolar, no parecen entender su papel en este tema. Aumentar la participación del gobierno y las comunidades en la formación profesional específica e interdisciplinaria de los docentes es una necesidad marcada cuando se desea la promoción de la salud en la escuela y en la comunidad, según lo recomendado por la OMS.

PALABRAS CLAVE: educador; salud; escuela; estilo de vida.

\section{Introdução}


No relatório da Conferência da Agenda Global sobre Saúde e Bem-estar, realizada pelo Fórum Econômico Mundial, em 2012, verificou-se que tendências recentes se tornaram proeminentes quanto ao novo conceito de progresso. Chegou-se-se à conclusão de que apesar da importância do crescimento econômico, este parece não ser suficiente para solucionar os problemas das nações. "Cada vez mais as pessoas sentem que é necessário mais; o que se quer é bem-estar. Em muitos países, tais como os EUA, a felicidade não tem aumentado a despeito do crescimento econômico". (WEF, 2012, p.5). Outra conclusão é que o futuro crescimento econômico se tornará mais difícil se também tivermos que evitar a desastrosa mudança climática. Em terceiro lugar está "o crescimento de uma nova ciência da felicidade, que provê evidência concreta sobre quais prioridades serão necessárias se nossas sociedades tiverem que alcançar níveis mais altos de bem-estar". (KAHNEMAN et al., 1999 apud WEF, 2012, p. 5)

A felicidade é reconhecida pela primeira vez, como um direito inalienável da pessoa humana, na Declaração de Independência dos Estados Unidos da América, de 1776. Assim reza seu segundo parágrafo:

Consideramos estas verdades por si mesmo evidentes, que todos os homens são criados iguais, sendo-lhes conferidos pelo seu Criador certos Direitos inalienáveis, entre os quais se contam a Vida, a Liberdade e a busca da felicidade. Que para garantir estes Direitos, são instituídos Governos entre os Homens, derivando os seus justos poderes do consentimento dos governados. (USA, 1776).

No estudo realizado por Scorsolini-Comin e Santos (2010), verificou-se que o termo "felicidade" tem sido traduzido no meio científico como bem-estar subjetivo (BES), sendo fortemente relacionado à promoção da saúde. Para os autores, as intervenções que possam contribuir para a melhoria do bem-estar subjetivo das pessoas implicarão diretamente nos conceitos de qualidade de vida, ou seja, nos conceitos de saúde.

A promoção da saúde mereceu um Artigo na Declaração Universal dos Direitos do Homem, promulgada em 1948, pela ONU, em que foi reconhecido o direito de toda pessoa ter "um padrão de vida capaz de assegurar a si e a sua família saúde e bem-estar [...]". (ONU, 1948, p.4).

Os estilos de vida podem ser definidos como 'o conjunto de hábitos e comportamentos de resposta às situações do dia-a-dia, 
apreendidos através do processo de socialização e constantemente reinterpretados e testados ao longo do ciclo de vida em diferentes situações sociais'. (MINISTÉRIO DA SAÚDE, 2004 apud FONTES, 2007, p. 57).

Foi durante a década de 1960 que o debate sobre a promoção da saúde abriu caminho para uma abordagem positiva nesse campo, com o objetivo de mudar a orientação que predominava até então, centrada apenas no controle da enfermidade. (BRASIL, 2002). Fontes (2007) ressalta as Conferências de Alma-Ata, em 1978, e Ottawa, em 1986, como pontos de convergência para a conformação de um novo paradigma nesse campo, enriquecidas com as declarações internacionais subsequentes formuladas em conferências sobre o tema.

Mas foi em 1981, na Primeira Conferência Nacional de Saúde, no Canadá, que o contexto social foi visto como um poderoso determinante da saúde, uma vez que moldava o comportamento individual, e admitido que a escolha do estilo de vida dependia da classe social. Desse modo, a promoção da saúde deixa sua base nos estilos de vida, para uma nova orientação centrada nos fatores sociais e ambientais. (BRASIL, 2002). O reforço da ação comunitária é adotado como uma fórmula para a promoção da saúde, o chamado empowerment, ou "empoderamento" da sociedade.

A World Health Organization - WHO, define saúde como "um estado de bem-estar completo, físico, mental e social, e não meramente a ausência de doença ou enfermidade". Frequentemente os esforços para promover a saúde deixam de atingir essa dimensão. (WHO, 1998, p.2).

É neste contexto que se insere a escola promotora da saúde.

O conceito de escola promotora da saúde, da OMS, é um exemplo do tipo de esforço que promove saúde em um sentido mais pleno. Este conceito abraça uma visão holística da saúde e leva em consideração as influências, tanto positivas quanto negativas sobre a saúde. (WHO, 1998, p.56).

Os dois objetivos da UNESCO e OMS - Educação para Todos e Saúde para Todos, respectivamente, têm recebido a contribuição de milhares de escolas ao redor do mundo, onde funcionários, alunos, pais e membros da comunidade trabalham juntos para ajudar suas escolas a se tornarem Escolas Promotoras da Saúde, e cujos esforços têm ajudado a ressaltar a visão de saúde que a OMS tem fomentado por mais de cinquenta anos. (UNESCO, 1998).

Segundo a Carta de Ottawa, de 1986, a "promoção da saúde é o nome dado ao processo de capacitação da comunidade para atuar na melhoria de sua 
qualidade de vida e saúde, incluindo uma maior participação no controle deste processo" Esse conceito reconhece o fato de que os cidadãos, apropriadamente capacitados, podem intervir na obtenção de mais saúde. "As pessoas não podem realizar completamente seu potencial de saúde se não forem capazes de controlar os fatores determinantes de sua saúde". (BRASIL, 2002, p.19).

Nessa conferência, realizada na cidade de Ottawa, no Canadá, a escola é mencionada como um dos espaços comunitários essenciais para esse tipo de capacitação.

É essencial capacitar as pessoas para aprender durante toda a vida, preparando-as para as diversas fases da existência, o que inclui o enfrentamento das doenças crônicas e causas externas. Esta tarefa deve ser realizada nas escolas, nos lares, nos locais de trabalho e em outros espaços comunitários. (BRASIL, 2002, p.24).

Além de desempenhar um papel fundamental na formação de valores, hábitos e estilos de vida, a escola é o local que reúne as melhores condições para implementação de ações de promoção da saúde.

Para a Associação Brasileira das Empresas de Refeições - ABERC, a escola é considerada um espaço de convivência e de troca de vivências. É a partir desse espaço que a experiência alimentar pode ser levada ao núcleo familiar. O programa de alimentação escolar e as boas práticas de alimentação estimulam na comunidade as melhores escolhas alimentares, mais saudáveis e sustentáveis. (ACCIOLY, 2009).

Já no Século XIX podia-se notar a percepção do potencial de influência da escola para uma mudança no estilo de vida das comunidades no seu entorno.

Paciente e dedicado esforço deve ser feito para o estímulo e elevação das comunidades circunvizinhas, para sua educação nos setores industriais e de saúde. A escola e todos os seus arredores devem ser lições objetivas que ensinem os caminhos do progresso e apelem ao povo por reformas, de modo que o gosto, a diligência e o refinamento possam tomar o lugar do que é grosseiro, impuro, da desordem, da ignorância e do pecado. (WHITE, 2007, p. 188).

Cientes desse papel de influência da escola, os gestores públicos da saúde elaboraram a Política Nacional de Promoção da Saúde, que propõe que as intervenções em saúde envolvam as ações e os serviços "que visem ao espaço para além dos muros das unidades de saúde e do sistema de saúde". Entre as estratégias para sua implementação está o "estímulo à criação de 
Rede Nacional de Experiências Exitosas na adesão e no desenvolvimento da estratégia de municípios saudáveis". A primeira experiência elencada é a identificação e apoio a iniciativas referentes às Escolas Promotoras da Saúde com foco em ações de alimentação saudável; práticas corporais/atividades físicas e ambiente livre de tabaco. (BRASIL, 2010, p.21).

O desenvolvimento de ações para a promoção da alimentação saudável no ambiente escolar é preconizado pela Política Nacional de Promoção da Saúde como uma das ações específicas para a promoção da alimentação saudável. Outras medidas envolvem a prevenção do tabagismo e a promoção do desenvolvimento sustentável, utilizando as escolas como um dos canais comunitários que mobilizem e incentivem ações contínuas.

Conforme Fontes (2007), as comunidades já dispõem de mecanismos para a participação dos jovens, incluindo os mais carenciados e marginalizados. Para ela, os adultos poderão contribuir para um planejamento dos cuidados de saúde, à medida que interajam com as crianças e compreendam suas reais necessidades.

Contudo, o poder público entende que o desenvolvimento de atitudes de vida saudável é um desafio para a educação, especialmente quanto à garantia de "uma aprendizagem efetiva e transformadora de atitudes e hábitos de vida". (BRASIL, 1998, p. 245).

Por este motivo foram elaborados os Parâmetros Curriculares Nacionais da Saúde, visando situar "a questão na realidade brasileira, indicando possibilidades de ação e transformação dos atuais padrões existentes na área de Saúde". (BRASIL, 1998, p. 245). Assim, a educação para a saúde passa a permear todas as áreas do currículo escolar, sendo tratada como tema transversal.

Um ponto fica bastante evidente: quando a escola deseja comprometer-se com a educação para a Saúde de seus alunos, além de funcionar como um espaço que oferece fortes referências para a prática e desenvolvimento de estilos de vida saudáveis, também inclui abordagem da temática da saúde nos diferentes componentes curriculares. (BRASIL, 1998, p.263).

Entre os conteúdos propostos para serem trabalhados de forma transversal, estão aqueles que dizem respeito à vida coletiva, tratando, por exemplo, das relações entre saúde e meio ambiente; a informação sobre os direitos da criança e do adolescente; a prevenção de acidentes; a prevenção contra as drogas, entre outros. 
Também em vida coletiva, o recurso da construção e atualização periódica de um quadro panorâmico da saúde, incluindo acontecimentos significativos do ponto de vista ambiental, a ocorrência de epidemias, fatos políticos e suas repercussões sobre a saúde, pesquisas e descobertas científicas, datas emblemáticas como o "Dia mundial de controle da Aids", permite a reelaboração e expressão das aspirações e projetos para a transformação social. (BRASIL, 1998, p. 283).

Apesar desses esforços, a visão holística da saúde, que leva em consideração o ser humano como um todo, conforme promovida pela OMS, tem sido pouco abordada ou simplesmente não tem sido, de forma alguma, pelos organismos promotores da saúde.

O ser humano tem várias dimensões e nem sempre dedica à dimensão física, que é a mais evidente, a atenção que ela merece. Também não se pode esquecer que as dimensões psíquica, social e espiritual da natureza humana influem de modo determinante no bem-estar, na saúde e na luta contra as doenças. (SCHNEIDER, 2004, p.14).

Para atingir essas dimensões Schneider (2004) propõe o uso de oito agentes naturais - a água e elementos do solo, o sol, o ar, o exercício físico, o repouso, a alimentação, a abstinência de drogas, e uma atitude mental positiva - como meios mais eficazes na conservação da saúde ou prevenção de doenças, e a incorporação desses remédios aos próprios hábitos de vida. Para ele, após uma enfermidade grave o paciente desenvolve uma atitude de mudança diante do mundo. Depois de uma situação limite tudo deixa de girar ao redor do próprio eu, o ser humano experimenta a ação de forças externas, que abalam sua autoconfiança e lhe abrem os olhos a valores transcendentes (SCHNEIDER, 2004, p.15).

Nos últimos anos várias pesquisas têm sido feitas no intuito de identificar as dificuldades enfrentadas na promoção da saúde na escola (LEONELLO; L'ABBATE, 2006; SILVA; HADDAD, 2006; CARVALHO, 2015; LOPES; NOGUEIRA; ROCHA, 2018). Leonello e Abbate (2006) afirmam que as práticas educativas em saúde têm se detido em ações preventivas, de caráter informativo e coercitivo, sobretudo nas escolas onde se configura uma prática pedagógica tradicional. Destaca-se também uma dificuldade de envolver a comunidade (CARVALHO, 2015). Estudos têm mostrado que a comunicação e articulação entre atores locais são frágeis e descontínuas (GOMES, 2009). No entanto, sabe-se que o 
trabalho em conjunto da sociedade civil organizada, pais, profissionais da saúde, educação, justiça, assistência social e outros é fundamental para diminuir a vulnerabilidade e promover a proteção à saúde, ajudando a promover comportamentos saudáveis por parte de adolescentes. Isso efetivamente contribuiria para a ressignificação da escola como espaço de promoção da cidadania. (LOPES, NOGUEIRA, ROCHA, 2018). Uma dessas pesquisas foi conduzida por Ferreira et al. (2013), uma equipe de enfermagem, que abordou a temática do cuidado da família como fator de mudanças no desenvolvimento escolar dos alunos, uma vez que estes apresentam alterações no comportamento e no rendimento escolar em decorrência da situação da relação familiar existente.

Por meio de uma pesquisa-ação, os autores apontam a relevância da promoção da saúde no meio escolar, uma vez que a escola favorece as atitudes mais saudáveis nos alunos, relacionadas às condições de sua saúde e qualidade de vida, e é o espaço básico para mediação das relações da família com os aspectos da saúde.

A necessidade de fortalecimento e renovação do vínculo familiar entre os componentes do núcleo familiar foi uma constatação que decorreu como resultado dessa pesquisa-ação. Embora fosse considerado um desafio para cada participante, pequenas transformações foram repercutidas no dia a dia das famílias e causaram uma melhora no convívio familiar, especialmente entre mãe e filhos. Os pesquisadores chegaram à conclusão de que o cenário escolar pode ser compreendido como um laboratório de promoção da saúde, e que as ciências da saúde devem preenchê-lo com projetos que ponham em discussão o autocuidado e a promoção para o viver saudável. Alunos, professores, famílias e coletividade constituem assim, uma diversidade de sujeitos que compõem o cenário escolar e requerem a contribuição de novos pesquisadores das diferentes áreas do saber.

Ainda no intuito de verificar as dificuldades enfrentadas na promoção da saúde na escola, podemos mencionar um estudo de caso, conduzido por Bógus e Santos (2007), que teve por objetivo a identificação do entendimento e da percepção que têm os educadores de uma escola pública da capital paulista relativamente ao tema da educação em saúde e promoção da saúde na escola, assim como as práticas desenvolvidas no ambiente escolar para promover um estilo de vida saudável.

Dois grandes grupos foram identificados nessa instituição educacional. Um, que concebe o trabalho em saúde como se reduzindo ao corpo biológico, com aproximação higienista; e o outro, que tem uma concepção especialista, que vê no professor de Ciências o profissional mais habilitado na 
escola para tratar do tema da educação, devido à sua formação profissional. De forma geral, verificou-se a tendência de professores pensarem a saúde de forma assistencialista e higienista, reduzida ao corpo biológico, com ações isoladas e sem articulação com parcerias dentro e fora da escola. Além disso, foi evidenciada a autoexclusão dos professores do processo de planejamento, esperando que isso ocorra por parte do diretor e coordenador pedagógico.

De fato, uma crítica comum aos programas de promoção da saúde na escola é justamente que esses são apresentados, em grande medida, por profissionais do setor de saúde e de forma verticalizada e desvinculada dos conteúdos do currículo (QUEIROZ et al., 2011). Oliveira, Martins e Bracht (2015), em uma pesquisa sobre a visão de professores de escolas de Vitória sobre as relações da Educação Física com o programa saúde na escola e Ferreira et al. (2014) perceberam que é necessário facilitar a comunicação, qualificar as discussões conceituais, melhorar a articulação entre profissionais da saúde e educação e estudantes no planejamento e desenvolvimento das ações em saúde.

A pesquisa de Bógus e Santos (2007) apontou a importância de conhecer e envolver-se com a realidade da escola, assim como a promoção de cursos de graduação, especialização e pós-graduação, e outras capacitações profissionais regulares que também possam ser planejadas e oferecidas pelos órgãos públicos, como meios para se avançar na Promoção da Saúde.

Para que ocorram as relações entre a escola, a família e as outras instituições, grupos e entidades que têm influência sobre a saúde, é necessário que não haja empecilhos, pois só assim será possível colocar a educação para a saúde no devido contexto e alcançar a necessária amplitude da ação educativa. Assim, podemos concluir que para as autoridades e pesquisadores que têm se debruçado sobre este assunto, o êxito na promoção da saúde e de um estilo de vida saudável junto à comunidade é algo que está intimamente relacionado à educação em geral, mas especialmente à escola, em particular.

Contudo, como indicou a pesquisa de Bógus e Santos (2007), enquanto os professores não forem conscientizados e formados quanto à responsabilidade da escola, e sua, própria, quanto ao seu protagonismo nas intervenções necessárias no ambiente escolar, no seu entorno, na comunidade escolar e na própria organização das estruturas escolares, as metas estabelecidas continuarão aquém das expectativas.

Diante desta realidade, o problema de pesquisa levantado visa identificar a percepção dos professores sobre o seu papel na promoção de hábitos e estilos de vida saudáveis no ambiente escolar.A hipótese que se levanta é que, devido a suas características naturais, a escola, e os professores, em particular, reúnem 
o potencial necessário para a execução das estratégias de implementação das políticas de promoção da saúde nas comunidades do seu entorno, mas não se julgam capazes de fazê-lo, possivelmente devido à falta de apoio formativo e de políticas públicas com esse propósito.

Como objetivo geral, pretendeu-se expor a compreensão e a percepção que os professores têm sobre o seu papel e respectiva importância para a promoção de valores, hábitos e estilo de vida saudável, bem como indicar possíveis medidas para que isso se torne uma realidade na comunidade escolar e em sua área de influência. De forma específica, foram levantados os fatores que impedem a execução de ações educativas específicas com vistas à promoção da saúde e de um estilo de vida saudável; identificar a compreensão dos professores sobre o seu papel no tratamento transversal do tema da promoção da saúde e estilo de vida saudável; verificar a existência e quantificar propostas de professores, relacionadas a projetos de promoção da saúde e estilo de vida saudável, para figurarem no Projeto Político Pedagógico - PPP da escola; e identificar fatores que exemplifiquem ações que visem à promoção da saúde e de um estilo de vida saudável na comunidade escolar.

\section{Metodologia}

\section{Tipo de pesquisa}

Conforme Jung (2003), em função dos objetivos a serem alcançados, teóricos ou práticos, pode haver vários tipos de pesquisa. Em geral os autores concordam que sob este ponto de vista, a pesquisa pode ser: Pesquisa exploratória; Pesquisa descritiva ou Pesquisa explicativa, pesquisa intervencionista, e aplicada.

Quanto aos fins, trata-se este trabalho de uma pesquisa descritiva, pois conforme Prodanov e Freitas (2013), é este o tipo de pesquisa que apenas registra e descreve os fatos observados sem interferir neles. Uma vez que este trabalho se valeu de artigos científicos publicados em periódicos, Prodanov e Freitas (2013), quanto aos meios, além de bibliográfica, trata-se também de pesquisa de campo. Quanto aos meios adotados na coleta de dados, a pesquisa foi feita através de um questionário online.

\section{Análise de dados}

Como se trata de uma pesquisa qualitativa, será utilizada a estatística descritiva para caracterização da amostra, análise de conteúdo e 
discussão dos dados.

\section{Sujeitos}

Ao todo, participaram da pesquisa 185 professores, do Ensino Fundamental 1 e 2 e Ensino Médio, de escolas públicas de Brasília e escolas públicasa e privadas do estado de São Paulo, principalmente as localizadas na região Metropolitana de Campinas, interior de São Paulo, sendo que 154 responderam todas as perguntas do questionário, ou, cerca de $83 \%$ dos participantes.

\section{Caracterização dos participantes no estudo}

A faixa etária dos participantes variou dos 21 aos 72 anos, sendo que a maior parte dos professores se situa na faixa etária entre os 30 e 49 anos. A grande maioria dos professores respondentes tem formação superior, com cerca de $55,19 \%$ dos participantes, sendo que $33,88 \%$ também possuem pós-graduação (Figura 1).

Figura 1 - Formação dos professores

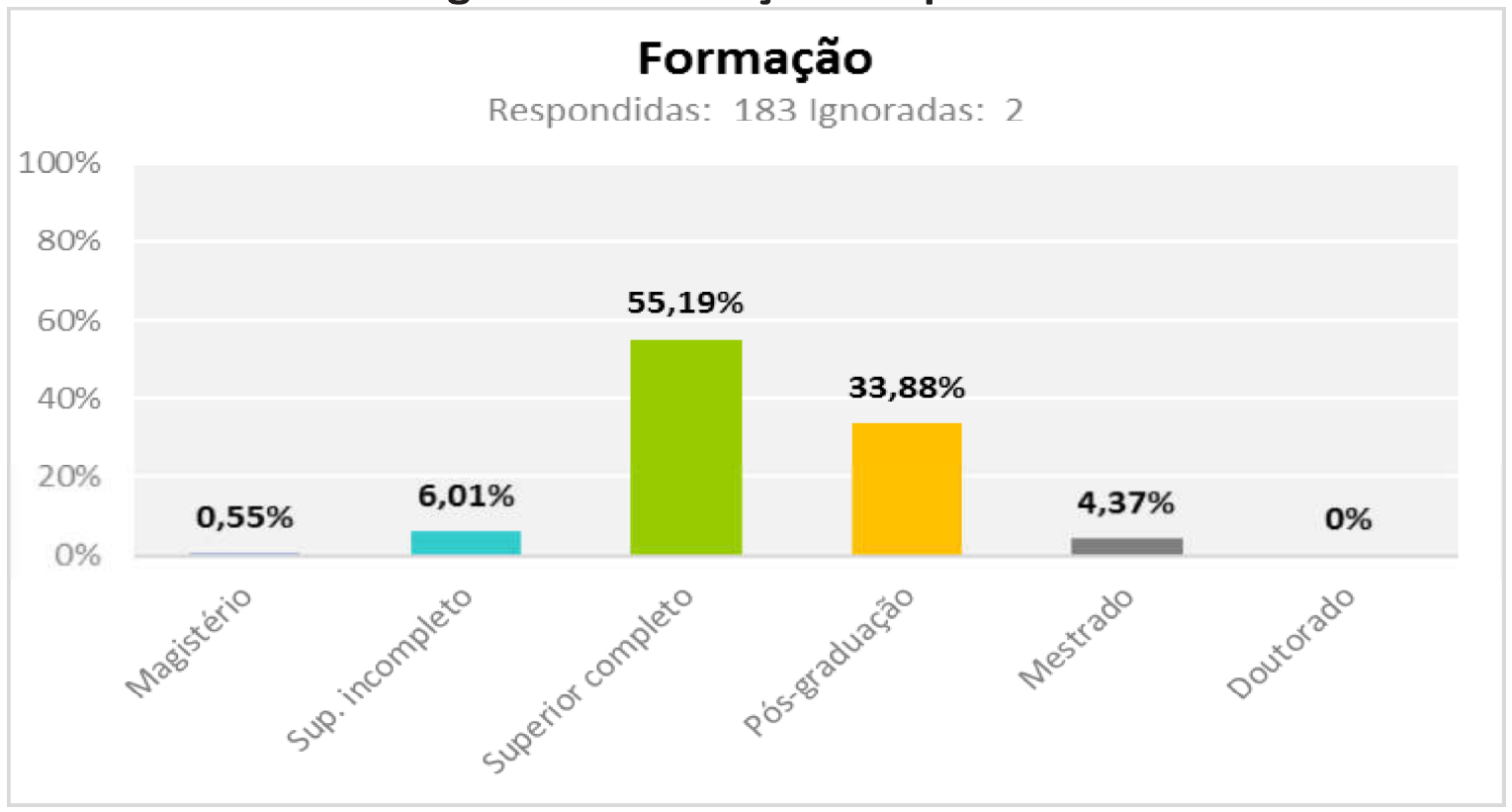

Fonte: Dados da pesquisa de campo dos autores.

Neste trabalho, os respondentes que lecionam no Ensino Fundamen-

Rev. Fac. Educ. (Univ. do Estado de Mato Grosso), Vol. 32, Ano 17, № 2, p. 189-213, jul./dez., 2019 (Epub Ahead of Print 15 set., 2019 ). 
tal 1, representam 57,22\%; no Ensino Fundamental 2, foram 22,78\% e 20\% no Ensino Médio, sendo que a maior parte dos professores participantes na pesquisa é da rede particular, representando $83 \%$ do total, e cerca de $17 \%$ são professores da rede pública. No estudo conduzido por Bógus e Santos (2007), sobre a percepção dos educadores sobre a escola promotora da saúde, a maior parte dos respondentes eram do Ciclo 2, do Ensino Fundamental.

\section{Instrumentos}

Esta pesquisa utilizou questionários autoaplicáveis, montados em um aplicativo online e distribuídos através de e-mails e redes sociais, na Internet, através de um link específico fornecido pelo aplicativo, que uma vez acessado registra o endereço IP - Internet Protocol do do computador do respondente.

$\mathrm{Na}$ primeira parte do questionário foram coletadas informações pessoais, de escolaridade, e profissionais, para identificação dos participantes.

Na segunda parte, foram abordados os temas: saúde na escola, promoção da saúde, parâmetros curriculares, saúde como Tema Transversal e o papel dos profissionais nas atividades escolares relacionadas à temática da saúde. Na terceira parte foram coletadas informações sobre o conhecimento específico dos professores quanto ao tema da escola promotora da saúde, assim como das ações formativas em que tomaram parte. Na última parte, foram levantadas informações sobre a percepção dos professores quanto ao uso dos recursos naturais para a promoção da saúde e de um estilo de vida saudável.

\section{Resultados e Discussão}

\section{Compreensão de educação em saúde, promoção da saúde e papel dos pro- fessores}

Diante da questão sobre o que o professor entende por educação em saúde, 44,51\% dos participantes escolheram a resposta sugerida: Estimular nos alunos a aquisição de hábitos de higiene e a adoção de modos de vida saudáveis, enquanto $50 \%$ optou pela resposta: Desenvolver conhecimentos, habilidades e destrezas que contribuíam para a adoção de formas de vida mais saudáveis (Figura 2). 
minado contexto, é fator essencial para atuar na modificação de comportamentos. É necessário saber que grande parte desse contexto comportamental faz parte do aprendizado sócio-cultural e somente pequena parte é de cunho pessoal. (GILBERT, 1990 apud LERVOLINO, 2000, p.32).

\section{Figura 2 - 0 que o professor entende por educação em saúde \\ O que você entende por educação em saúde?}

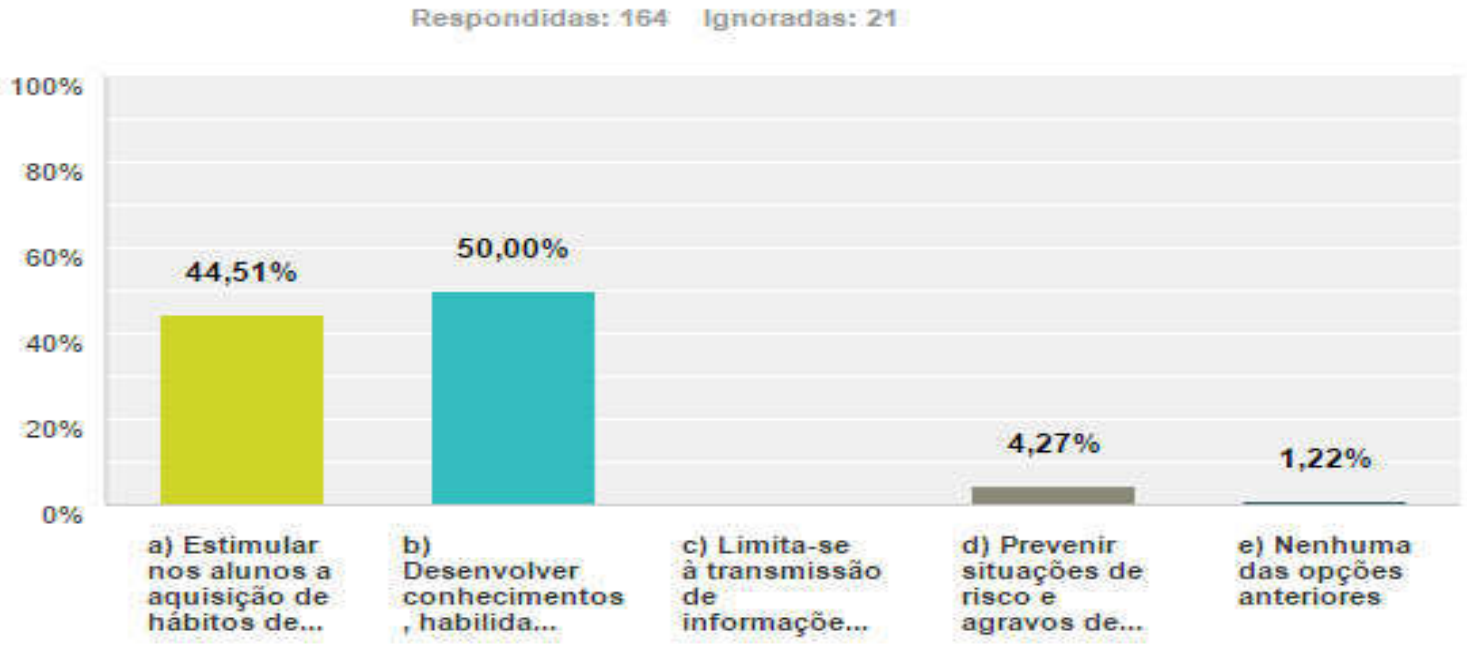

Fonte: Dados da pesquisa de campo dos autores.

Perguntados sobre a importância de trabalhar com o tema educação em saúde na escola, entre os 163 professores que responderam a esta questão, 46,63\% concordaram com a resposta sugerida de que sim, é importante, pois este é um tema que está relacionado com a família e com a comunidade, enquanto 30,06\% também crê que o tema é importante e que o mesmo deve fazer parte do dia a dia do aluno e do planejamento da escola. Outros $23,31 \%$ acham que a saúde é muito importante e essa noção deve ser passada pela escola. Nenhum dos participantes crê que este tema não deva ser trabalhado na escola (Figura 3).

A importância de introduzir a escola como promotora da saúde na infância e na adolescência é reforçada pelo conceito de educação no âmbito escolar, que visa o aprendizado de elementos baseados em valores positivos e apoiados em vivências e práticas escolares (LERVOLINO, 2000). 
Figura 3 - Importância de trabalhar o tema educação em saúde na escola

Você acha importante trabalhar com o tema educação em saúde na escola?

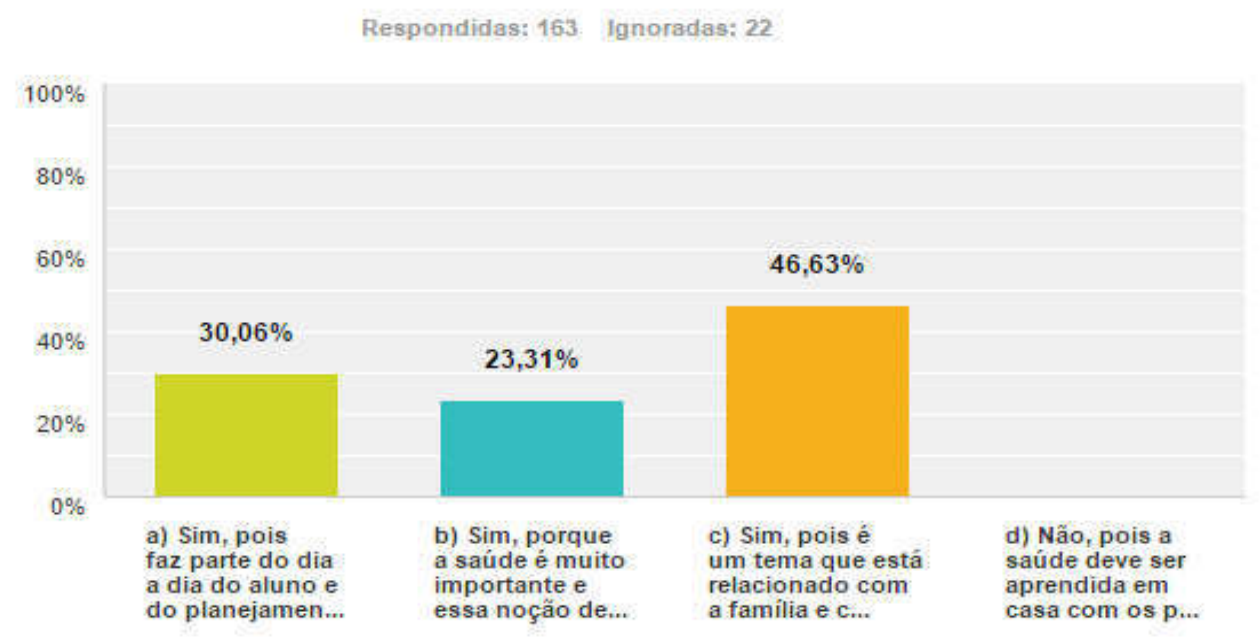

Fonte: Dados da pesquisa de campo dos autores.

Questionados sobre o papel dos profissionais da escola quanto às atividades de promoção da saúde na escola, as respostas dos professores se distribuíram praticamente de forma igual entre o planejamento $(29,19 \%)$, implantação $(30,43 \%)$ e a execução $(30,43 \%)$.

De modo geral, os professores parecem julgar que não seja seu papel a atividade de avaliar este tema na escola. Somente $0,62 \%$ considera ser este o seu papel, conforme Figura 4.

\section{Figura 4 - Papel dos profissionais da escola quanto às atividades de promoção da saúde na escola}

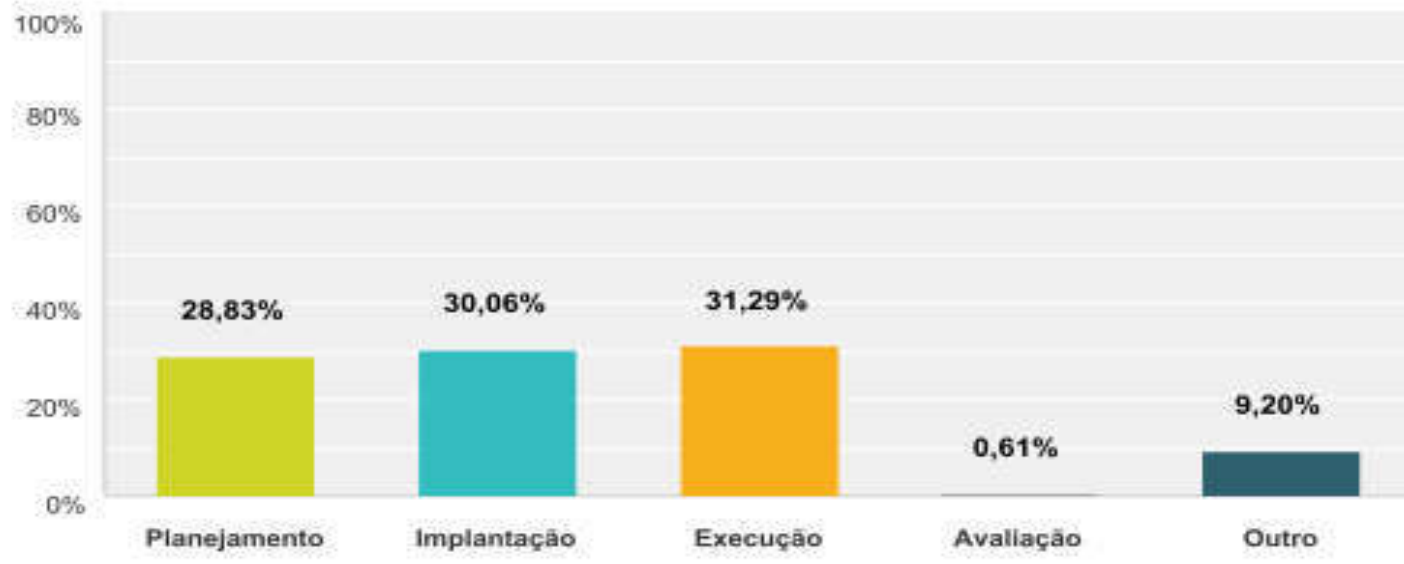

Fonte: Dados da pesquisa de campo dos autores. 
Embora metade dos professores pesquisados (51,22\%) entenda que a abordagem dos temas relacionados à saúde deve ser em atividades específicas, como feiras de saúde, orientação sexual etc., praticamente a outra metade $(48,78 \%)$ crê que estes temas devem ser abordados nos conteúdos das disciplinas de Ciências e Biologia, por exemplo, (Figura 5).

\section{Figura 5 - Forma de abordagem dos temas relacionados com saúde nas atividades escolares}

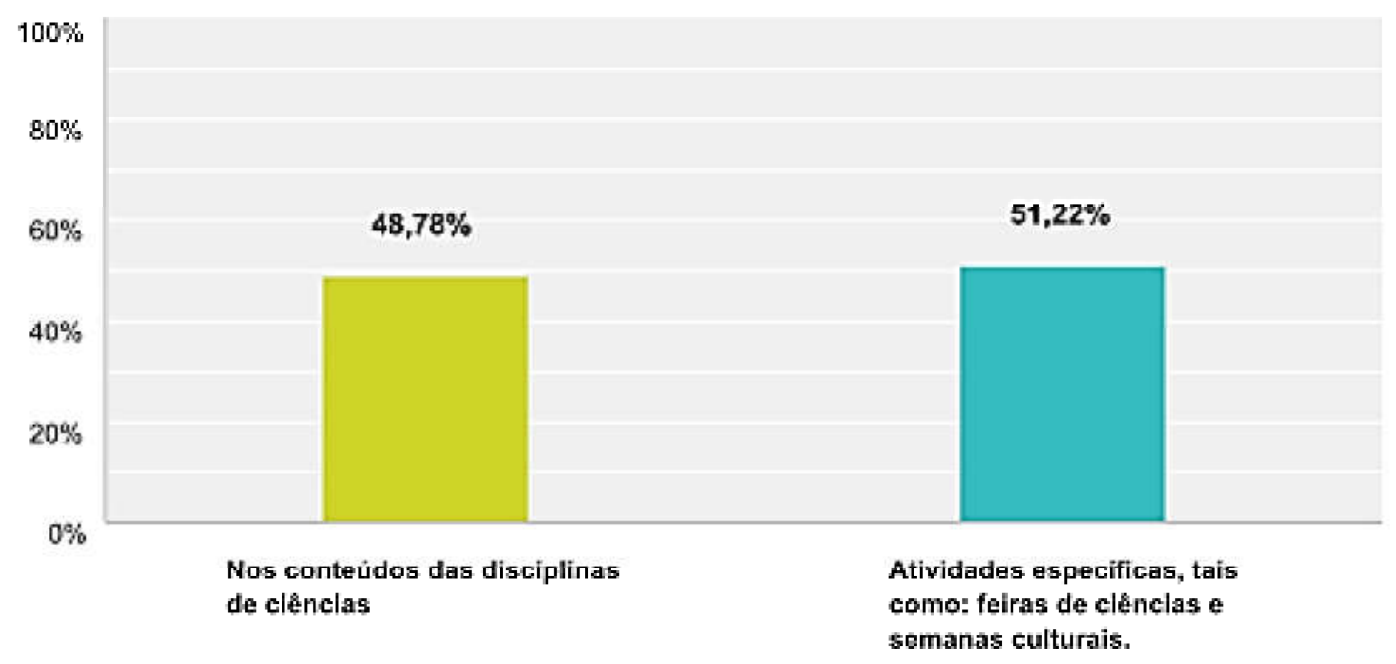

Fonte: Dados da pesquisa de campo dos autores.

Essa concepção especialista, na qual o responsável pelo tema de educação em saúde seria o professor de Ciências, exclusivamente, por ser ele o mais habilitado para isso, pela sua formação profissional, também é verificado no estudo Bógus e Santos (2007), embora nessa pesquisa, essa concepção é ressaltada como sendo prevalecente entre os professores pesquisados.

Em relação à afirmação de que a promoção da saúde no âmbito escolar busca oferecer conhecimentos e habilidades para a melhoria das condições de saúde da comunidade escolar, por meio da educação para a saúde, a grande maioria dos respondentes $(78,31 \%)$ manifestaram concordar muito, enquanto $19,88 \%$ manifestaram concordar parcialmente (Figura 6). Esse dado nos permite observar que os professores têm uma boa percepção sobre os objetivos da promoção da saúde no âmbito escolar através da educação para a saúde. 
Figura 6 - Posição dos professores sobre a promoção da saúde no âmbito escolar, para melhoria das condições de saúde da comunidade escolar, por meio da educação para a saúde.

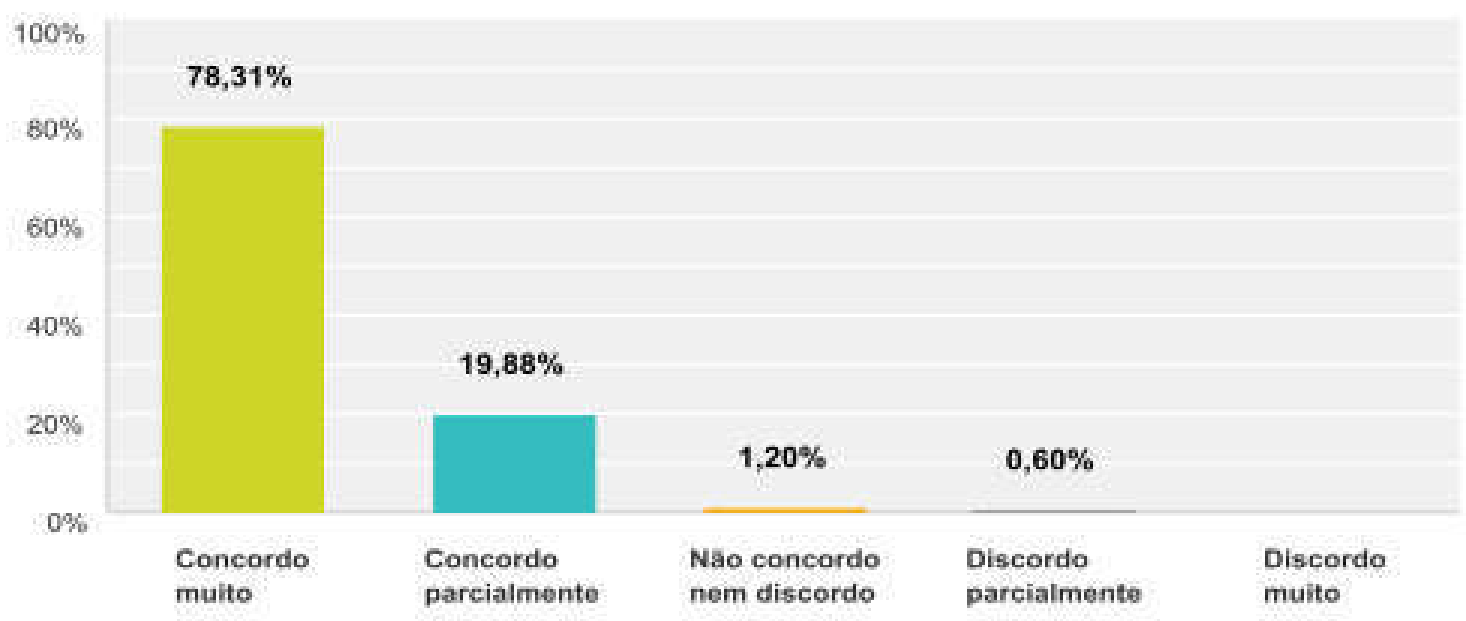

Fonte: Dados da pesquisa de campo dos autores.

Os respondentes também manifestaram grande concordância quanto à responsabilidade do professor pela inclusão do tema transversal saúde nas disciplinas que lecionam, pois $65,06 \%$ concordaram muito com essa afirmação, enquanto $28,92 \%$ concordaram parcialmente (Figura 7 ).

Conforme Lervolino (2000) percebe-se nas justificativas dos professores a preocupação em educar para a saúde, mas ressaltam a importância de cada aluno dar à saúde um valor positivo e que possua conhecimentos que Ihe ajude e aos que estão à sua volta.

Figura 7 - Posição dos professores sobre a sua responsabilidade pela inclusão do tema transversal saúde nas disciplinas que lecionam

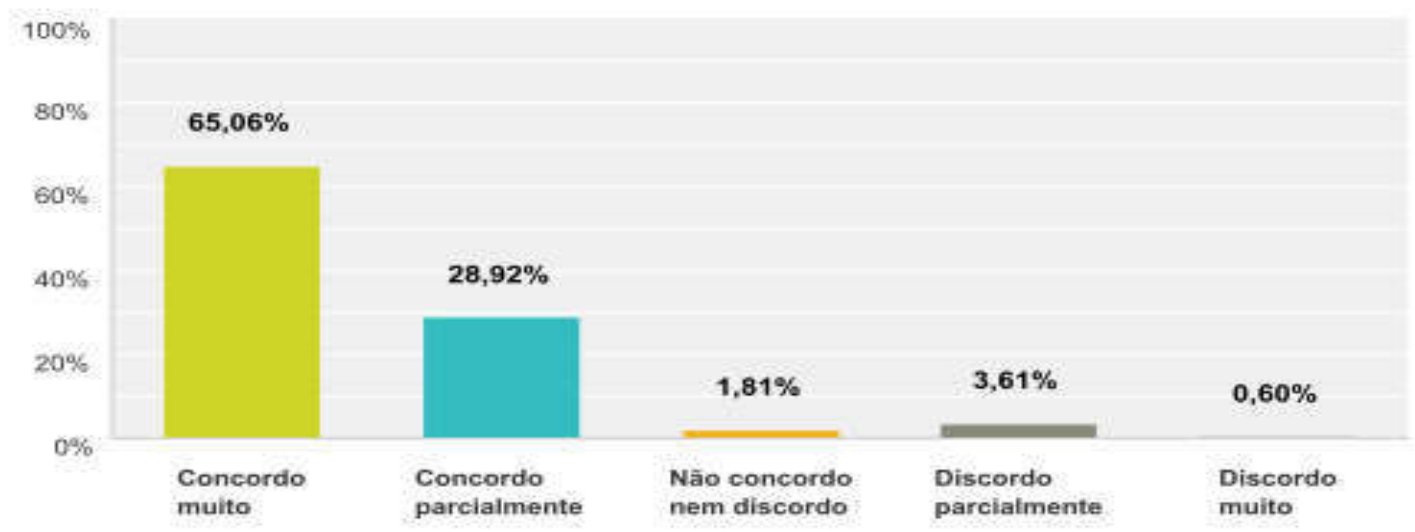

Fonte: Dados da pesquisa de campo dos autores. 
A participação dos alunos e pais, de forma ativa e autônoma, na discussão e definição de quais comportamentos devem ser trabalhados para a promoção da saúde, é algo com o que a grande maioria dos professores concorda (71,69\%). No entanto, $24,7 \%$ dos pesquisados manifestaram concordar parcialmente com essa assertiva (Figura 8 ).

Figura 8 - Posição dos professores sobre a necessidade da participação dos alunos e pais na discussão e definição de quais comportamentos deve ser trabalhados para a promoção da saúde

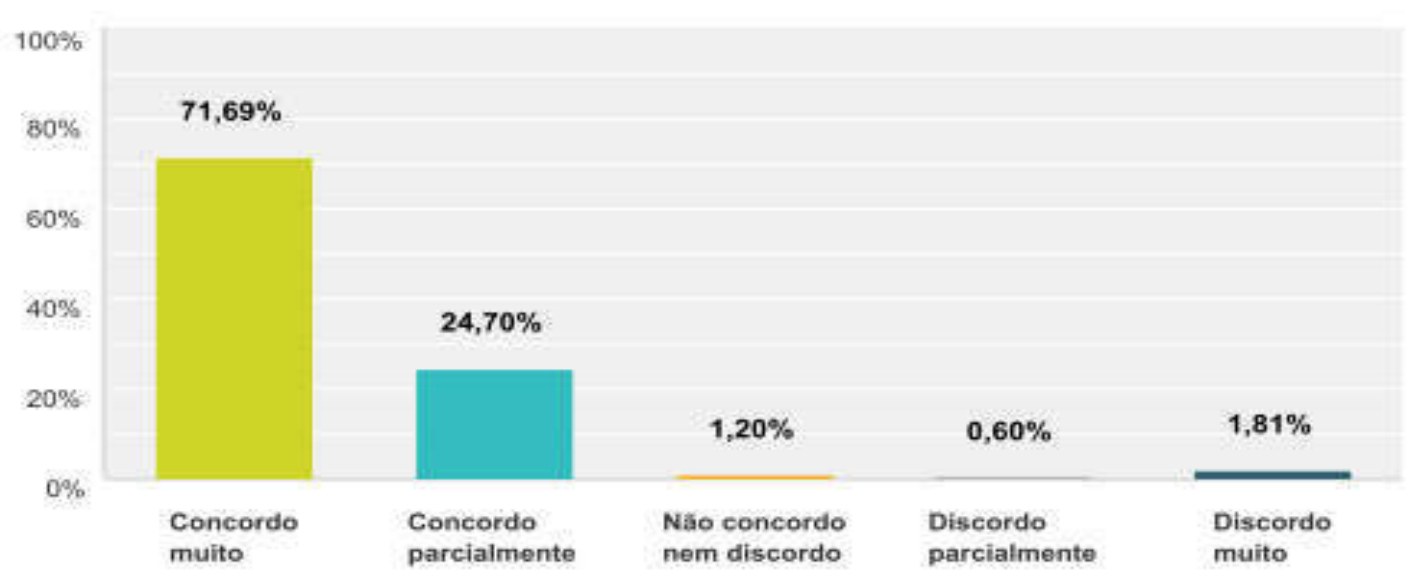

Fonte: Dados da pesquisa de campo dos autores.

Conhecimento específico e participação em ações formativas sobre o tema

Em relação à participação dos professores na elaboração do Projeto Político Pedagógico - PPP da sua escola, com propostas relacionadas a projetos de promoção da saúde e estilo de vida saudável, podemos perceber que entre os professores pesquisados, há um conhecimento razoável sobre o tema, pois a maioria soube indicar a presença desses projetos no PPP da sua escola, sendo que $39,76 \%$ informaram haver mais de 3 projetos de professores e $22,29 \%$ informaram haver menos de 3 projetos. No entanto, 31,93\% sequer sabem informar (Figura 9).

Conforme Silva (2010), o projeto político pedagógico oferece uma perspectiva de compreensão, de escuta e de participação social, constituindo-se como um instrumento participativo que ajuda a redimensionar uma nova 
relação com o setor Saúde.

Figura 9 - Quantidade de propostas relacionadas a projetos de promoção da saúde e estilo de vida saudável, sugerida por professores.

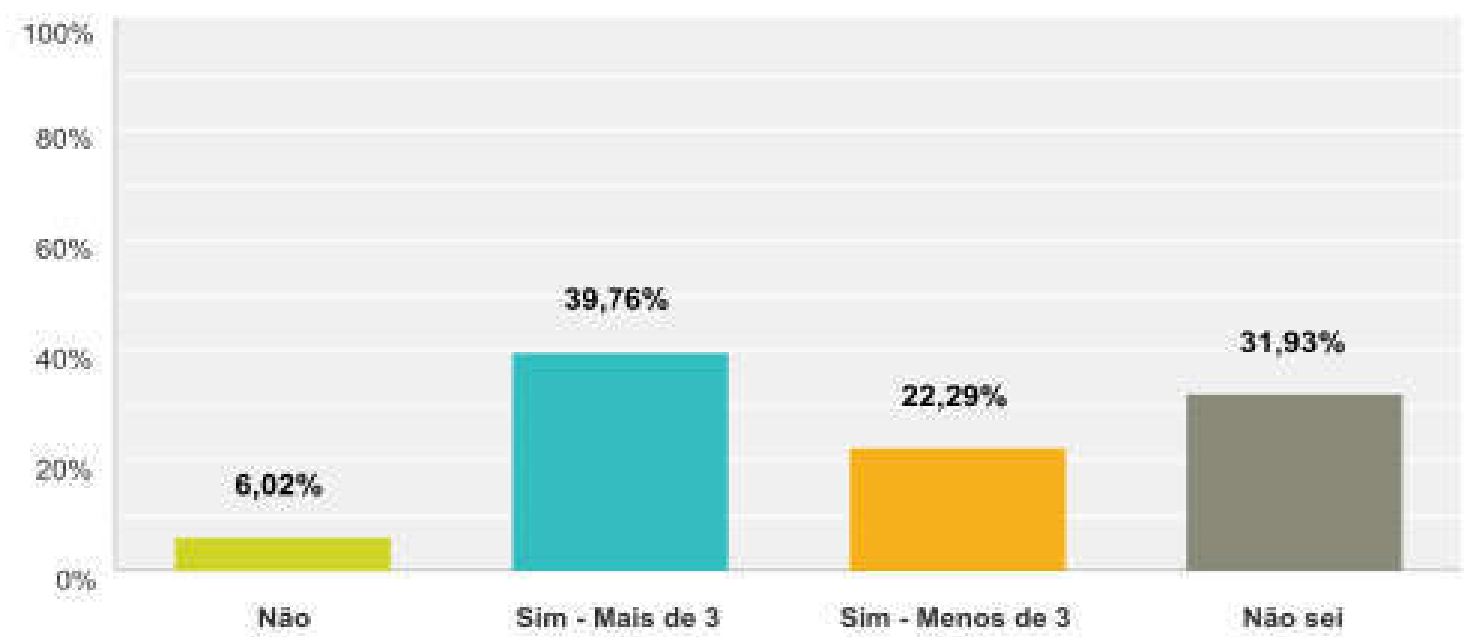

Fonte: Dados da pesquisa de campo dos autores

No questionário foi apresentada aos professores uma questão aberta sobre o seu entendimento do termo "escola promotora da saúde". Entre as respostas dos 135 respondentes podemos notar que, de maneira geral, os professores entendem os princípios envolvidos nesse termo, especialmente a importância do papel da escola para influenciar a comunidade escolar e as famílias dos alunos a adotar um estilo de vida saudável. No entanto, a escola parece ser vista por esses respondentes como uma entidade dissociada dos seus professores, e a ideia de ação educativa para atingir esses objetivos se restringe a eventos esporádicos sobre o tema, como feiras de ciências e semanas culturais.

Quanto à participação dos professores em ações de formação sobre o tema da escola promotora da saúde, pudemos apurar que a grande maioria nunca participou desse tipo de formação $(64,71 \%)$, enquanto $18,3 \%$ chegou a participar há menos de um ano e 11,76\%, entre 1 a 5 anos. 


\section{Figura 10 - Idade da participação em formação específica para professor, sobre o tema de escola promotora da saúde.}

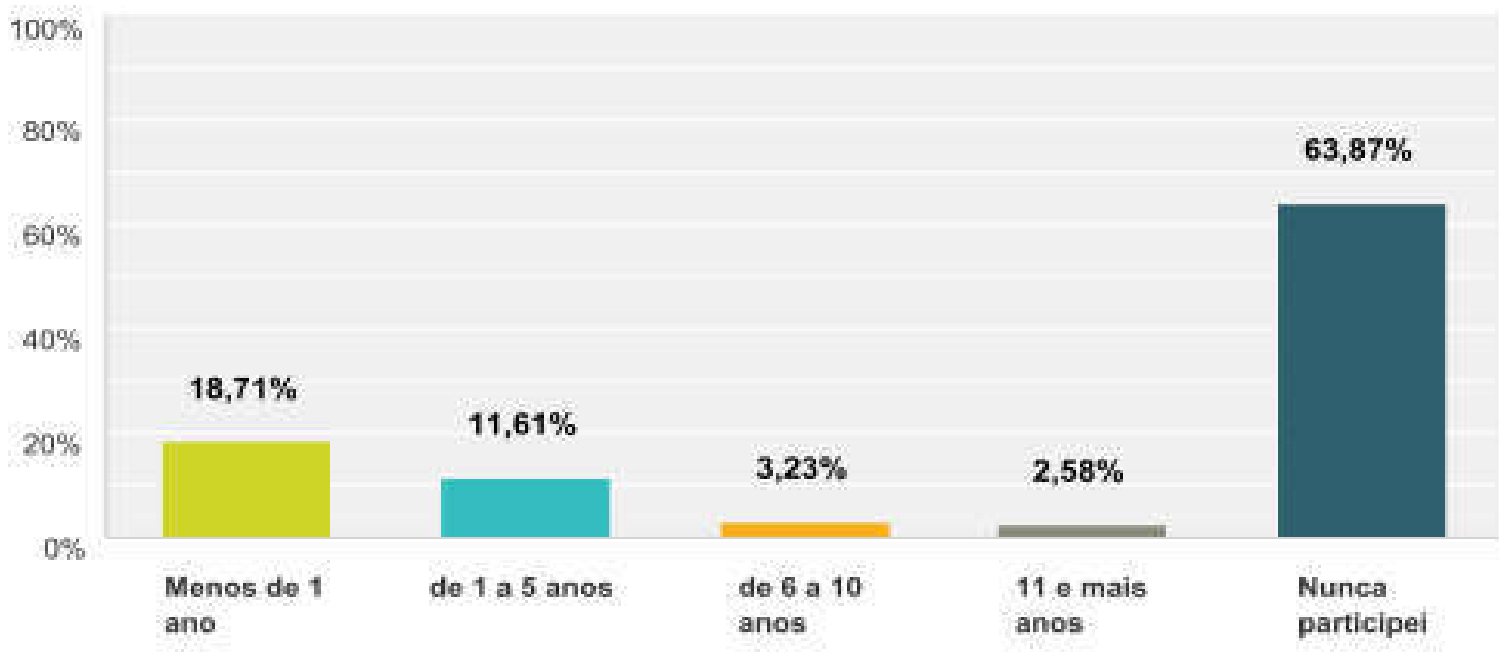

Fonte: Dados da pesquisa de campo dos autores

Assim, para uma escola trilhar os caminhos da Promoção da Saúde, o conhecimento e o envolvimento com a realidade local são fundamentais, aliados a uma boa formação profissional, com cursos de graduação, especialização e pós-graduação, de capacitação profissional, que mantenham uma regularidade e possam ser também planejados e ofertados pelos órgãos públicos. (BÓGUS; SANTOS, 2007, p. 131).

Também pudemos apurar que apenas $9,21 \%$ dos respondentes participaram de alguma formação específica para professor de escola promotora da saúde, promovida por instituição pública, enquanto 29,61\% já participou desse tipo de formação, mas em instituição privada (Figura 11). 
Figura 11 - Tipo de instituição em que os respondentes já participaram de uma formação específica para professor de escola promotora da saúde

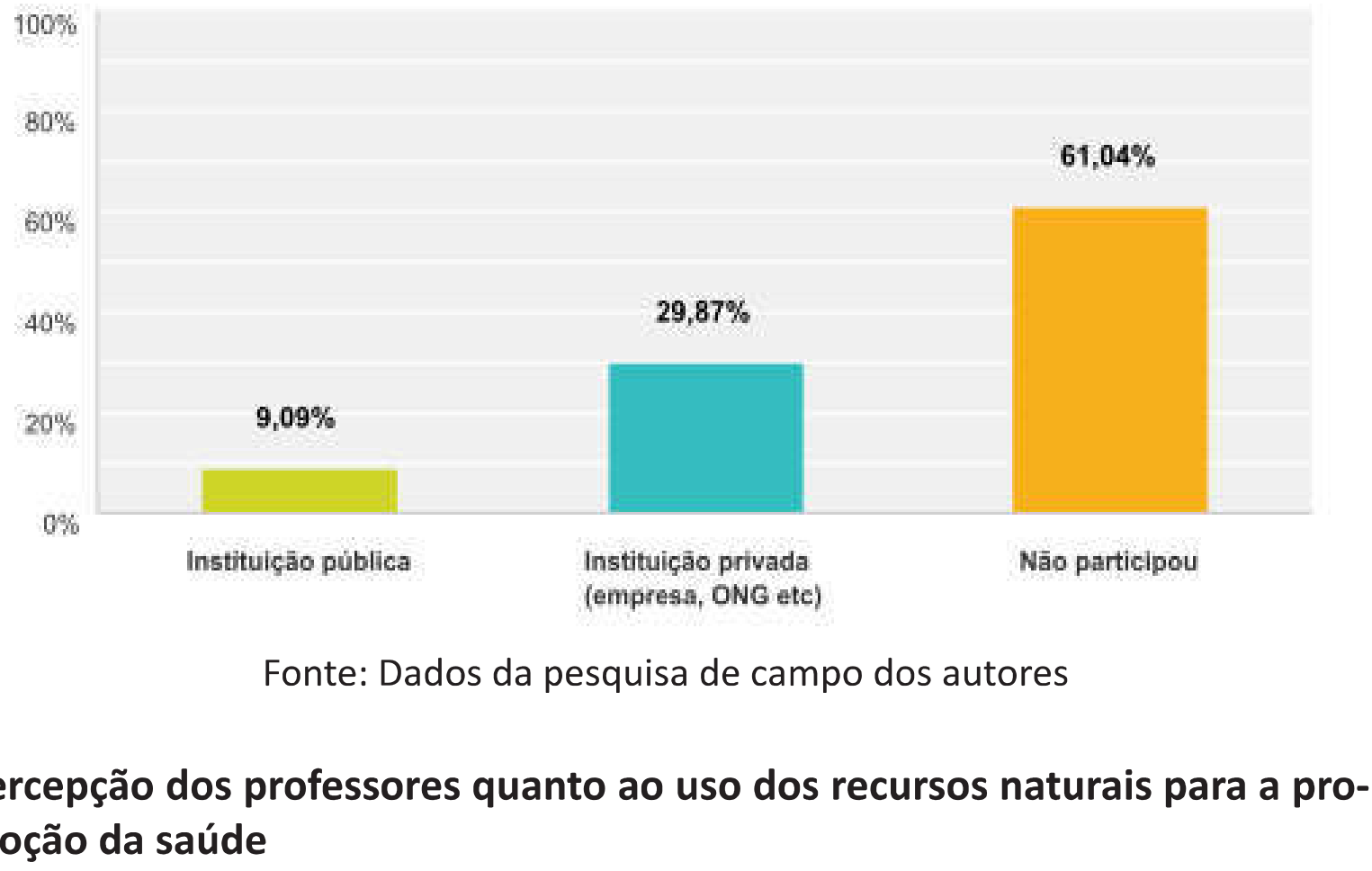

Entre as oito práticas naturais de prevenção e manutenção da saúde do professor e seus alunos, indicadas no questionário, a nutrição adequada $(94,84 \%)$, o exercício físico e o uso da água (com 93,55\%, cada) foram assinaladas como as mais importantes, embora as demais práticas também tenham recebido grande destaque (Tabela 1 ).

Tabela 1 - Itens que o professor acha importantes para a sua saúde e de seus alunos

\begin{tabular}{|c|c|}
\hline Opções de resposta & Percentual \\
\hline Nutrição adequada & $94,84 \%$ \\
\hline Exercício Físico & $93,55 \%$ \\
\hline Uso da Água & $93,55 \%$ \\
\hline Exposição ao Sol & $81,94 \%$ \\
\hline Moderação & $76,13 \%$ \\
\hline Ar Puro & $85,16 \%$ \\
\hline
\end{tabular}




\begin{tabular}{|c|c|}
\hline Descanso & $87,10 \%$ \\
\hline Espiritualidade & $87,74 \%$ \\
\hline
\end{tabular}

Fonte: Dados da pesquisa de campo dos autores.

O uso da água (87,58\%) e a espiritualidade $(88,24 \%)$ foram indicados pelos participantes como sendo os itens que mais são praticados por eles, seguidos do descanso, com $60,78 \%$ (Figura 12 ).

\section{Figura 12 - Itens mais praticados pelos professores}

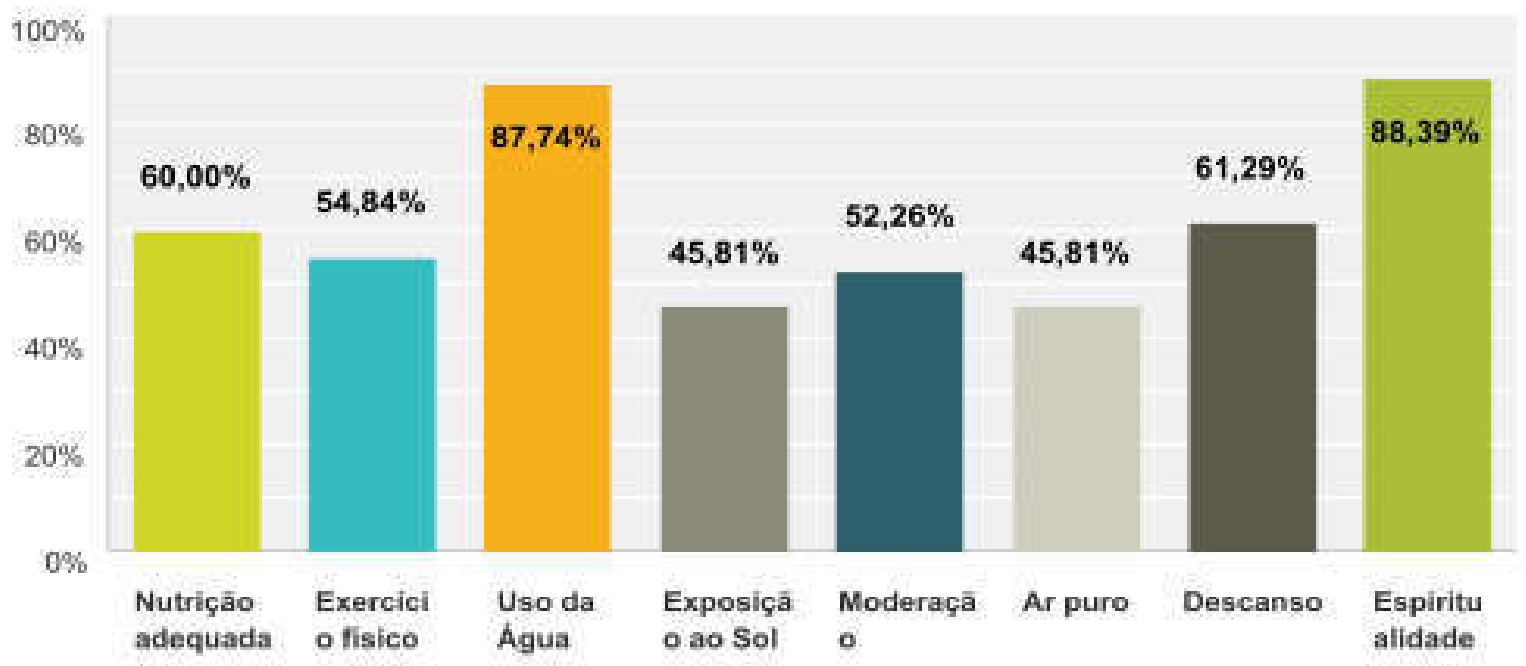

Fonte: Dados da pesquisa de campo dos autores.

Também é interessante notar que entre as oito práticas naturais de prevenção e manutenção da saúde, o item mais indicado pelos professores como sendo o de que mais necessitam de formação específica para trabalhar com seus alunos, é a nutrição adequada $(80,85 \%)$, seguida do exercício físico com $52,48 \%$. Ainda merecem destaque a moderação, com $26,24 \%$ e a espiritualidade, com 25,53\%. (Figura 13). 
Figura 13 - Itens que os professores indicaram mais necessitarem de formação específica para trabalhar com seus alunos

Dos itens relacionados abaixo assinale aqueles para os quais você precisaria formação específica para trabalhar com seus alunos:

Respondidas: 141 Ignoradas; 44

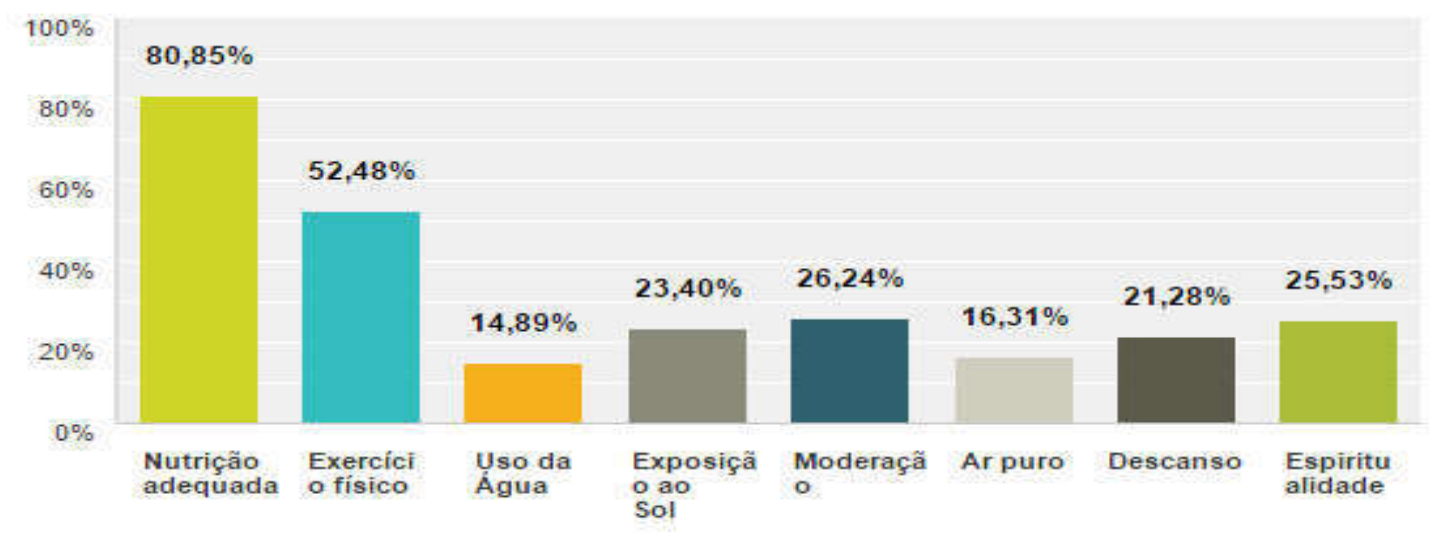

Fonte: Dados da pesquisa de campo dos autores.

\section{Considerações finais}

Com base no levantamento feito através desta pesquisa, verificou-se que os professores entendem a necessidade da promoção da saúde no ambiente escolar e os seus objetivos, mas os mesmos não parecem compreender o seu papel no desenvolvimento desse tema na escola.

Também se verificou a ausência de formação específica sobre a escola promotora da saúde, seja em nível governamental ou privado, assim como orientações específicas sobre as práticas naturais para a prevenção e manutenção da saúde dos professores e alunos.

Assim, conclui-se que para ocorrer a promoção da saúde na escola e, através da escola, na comunidade, como preconizado pela OMS, é necessária a ampliação do conhecimento e do envolvimento de governo e sociedade civil, aliados a uma formação profissional específica e interdisciplinar em cursos de graduação, especialização, pós-graduação e de capacitação profissional, de forma regular e planejada, de acordo com o PPC (Projeto Pedagógico de Curso) e com o envolvimento das equipes da escola com a comunidade. 


\section{Referências}

ACCIOLY, E. A escola como promotora da alimentação saudável. Ciência em Tela. Rio de Janeiro, RJ, v. 2, n. 2, p. 1-9, 2009. Disponível em: http://www. cienciaemtela.nutes.ufrj.br/artigos/0209accioly.pdf. Acesso em: 5 maio 2014.

BÓGUS, C.M. A; SANTOS, K.F. A percepção de educadores sobre a escola promotora de saúde: um estudo de caso. Revista brasileira de crescimento e desenvolvimento humano, São Paulo, v.17, n.3, p.1-10, dez. 2007. Disponível em: <http://pepsic.bvsalud.org/scielo.php?pid=S010412822007000300013\&script=sci_arttext>. Acesso em: 25 nov. 2014.

BRASIL. Ministério da Saúde. Secretaria de Políticas de Saúde. Projeto Promoção da Saúde. As Cartas da Promoção da Saúde / Ministério da Saúde, Secretaria de Políticas de Saúde, Projeto Promoção da Saúde - Brasília:Ministério da Saúde, 2002.

BRASIL. Ministério da Saúde. Secretaria de Vigilância em Saúde. Secretaria de Atenção à Saúde. Política Nacional de Promoção da Saúde / Ministério da Saúde, Secretaria de Vigilância em Saúde, Secretaria de Atenção à Saúde. - 3. ed. - Brasília:Ministério da Saúde, 2010.

BRASIL. Secretaria de Educação Fundamental. Parâmetros curriculares nacionais: terceiro e quarto ciclos do ensino fundamental: introdução aos parâmetros curriculares nacionais / Secretaria de Educação Fundamental. PCN Saúde. Brasília: MEC/SEF, 1998.

CARVALHO, F. F. B. de. A saúde vai à escola: a promoção de saúde em práticas pedagógicas. Physis Revista de Saúde Coletiva, Rio de Janeiro, v. 25, n. 4, p. 1207-1227, 2015.

FERREIRA, I. R. C.; MOYSÉS, S. J.; FRANÇA, B. H. S. et al. Percepções de gestores locais sobre a intersetorialidade no Programa Saúde na Escola. Rev. Bras. Educ., v. 19, n. 56, p. 61-76, 2014.

FERREIRA, C.L. L; LACERDA, M.R.; RANGEL R. F; SANTINI, R. G.; SCHMITT, A. C. A. Mudanças no comportamento e desenvolvimento do escolar a partir do cuidado à família. Revista Brasileira de Enfermagem, Brasília, v. 66, n. 5, p. 1-7, set/out. 2013. Disponível em: <http://www.scielo.br/scielo.php?scrip$\mathrm{t}=\mathrm{sci}$ _arttext\&pid=S003471672013000500007>. Acesso em: 25 nov. 2014.

FONTES, R. M. F.V. Promoção de Estilos de Vida Saudáveis nas Crianças e Adolescentes. Porto, 2007. 311f. Dissertação (Mestrado em Ciências de Enfermagem) - Universidade do Porto, Porto, 2007.

Rev. Fac. Educ. (Univ. do Estado de Mato Grosso), Vol. 32, Ano 17, № 2, p. 189-213, jul./dez., 2019 (Epub Ahead of Print 15 set., 2019 ). 
JUNG, C. F. Metodologia Científica: Ênfase em Pesquisa Tecnológica. 3 Ed. 2003. Disponível em: <http://www.mecanica.ufrgs.br/promec/alunos/ download/metodolo.pdf>. Acesso em 20 ago. 2014.

GOMES, J. P. As Escolas Promotoras de Saúde: uma via para promover a saúde e a educação para a saúde da comunidade escolar. Educação, v. 32, n. 1, p. 84-91, 2009.

LEONELLO, V. M.; L'ABBATE, S. Educação em Saúde na escola: uma abordagem do currículo e da percepção de alunos de graduação em Pedagogia. Interface - Comunic. Saúde, Educ., Botucatu, v. 10, n. 19, p. 149-166, jan./jun. 2006.

LERVOLINO, S. A. Escola Promotora da Saúde - Um Projeto de Qualidade de Vida. São Paulo, 2000. 167f. Dissertação (Mestrado em Saúde Pública) Universidade de São Paulo, São Paulo, 2000. Disponível em: <www.teses.usp.br/teses/ disponiveis/6/6135/tde-01072006-211720/>. Acesso em 2 out. 2016.

ONU. Declaração Universal dos Direitos Humanos. Disponível em: <portal. mj.gov.br/sedh/ct/legis_intern/ddh_bib_inter_universal.htm> Acesso em 7 maio 2014.

LOPES, I. E.; NOGUEIRA, J. A. de; ROCHA, D. G. Eixos de ação do programa saúde na escola e promoção da saúde: revisão integrativa. Saúde Debate, Rio de Janeiro, v. 42, n. 118, p. 773-389, jul.-set. 2018.

OLIVEIRA, V. J. M.; MARTINS, I. R.; BRACHT, V. Relações da Educação Física com o Programa Saúde Na Escola: visões dos Professores das escolas de Vitória/ES. Pensar Prát., v. 18, n. 3, p. 544-556, 2015.

PRODANOV, C. C.; FREITAS, E. C. Metodologia do Trabalho Científico: Métodos e Técnicas da Pesquisa e do Trabalho Acadêmico. 2 Ed. Novo Hamburgo: Freevale, 2013. Disponível em: <http://docente.ifrn.edu.br/ valcinetemacedo/disciplinas/metodologia-do-trabalho-cientifico/e-bookmtc>. Acesso em 18 set. 2014.

QUEIROZ, M. V. O.; LUCENA, N. B., BRASIL, E. G. M., et al. Cuidado ao adolescente na atenção primária: discurso dos profissionais sobre o enfoque da integralidade. Rev. da Rede Enferm. do Nord., v. 12, n. esp. p. 1036-1044, 2011.

SCHNEIDER, E. A Cura e a Saúde Pela Natureza: Como prevenir e tratar doenças. 2 Ed. Tatuí: Casa Publicadora Brasileira, 2004.

SCORSOLINI-COMIN, F.; SANTOS, M.A. O estudo científico da felicidade: revisão integrativa da literatura. Disponível em: <http://www.scielo.br/pdf/rlae/ v18n3/pt_25.pdf>. Acesso em 7 maio 2014. 
SILVA, C. S. Promoção da saúde na escola: modelos teóricos e desafios da intersetorialidade no Município do Rio de Janeiro. Rio de Janeiro, 2010. Dissertação (Doutorado) Escola Nacional de Saúde Pública Sérgio Arouca. Rio de Janeiro, 2010. Disponível em: <bvssp.icict.fiocruz.br/lildbi/docsonline/get. php?id=3295>. Acesso em 9 out. 2016.

SILVA, J. A. A.; HADDAD, F. Prefácio. In: BRASIL. Ministério da Saúde. Escolas promotoras de saúde: experiências do Brasil. Brasília: Ministério da Saúde, Organização PanAmericana da Saúde, 2006. 272p. (Série Promoção da Saúde, n. 6)

UNESCO. Health-Promoting Schools - Promoting the World Health Organisation's concept of health. Connect - Unesco International Science, Technology \& Environmental Education Newsletter, Paris, v.23, n. 2, p. 1-16, 1998. Disponível em: <http://www.education.unesco.org/educprog/ste/index.html>. Acesso em 20 ago. 2015.

USA. The U.S. National Archives \& Records Administration. The Declaration of Independence: A Transcription. 1776. Disponível em: <http://www.archives. gov/exhibits/charters/declaration_transcript.html>. Acesso em 7 maio 2014.

WEF. Well-being and Global Success. Geneva, 2012. World Economic Forum. Disponível em: < http://www3.weforum.org/docs/WEF_HE_GAC_WellbeingGlobalSuccess_Report_2012.pdf>. Acesso em 1 set. $20 \overline{1} 5$.

WHITE, E.G. Conselhos Sobre Educação. Casa Publicadora Brasileira. Disponível em: <www.ellenwhitebooks.com>. Acesso em 7 maio 2014.

WHO. (1996). Research to Improve Implementation and Effectiveness of School Health. Disponível em < http://apps.who.int/iris/bitstream/10665/63366/1/ WHO_HPR_HEP_96.3.pdf>, Acesso em 26 de outubro de 2017.

Data de recebimento: 29.03.2019

Data de aceite: 15.08.2019 